\title{
Critical Factors Affecting the Intention to Adopt Big Data Analytics in Apparel Sector, Sri Lanka
}

\author{
Hiruni Bolonne ${ }^{1}$ \\ Department of Accounting \\ University of Sri Jayewardenepura \\ Colombo, Sri Lanka
}

\author{
Piyavi Wijewardene ${ }^{2}$ \\ Odiliya Virtual Technologies (Pvt) Ltd \\ Colombo, Sri Lanka
}

\begin{abstract}
Big data has become a potential research area in apparel industry due to vast amount of data generated in a short period of time. However, the inability to adapt to the challenging and digital environment has pulled out the weaker from the industry while growing the adopters more and more powerful players. As the insights generated out of data becoming core competitive advantages, now it is pertinent to identify which factors would affect the intention to adopt big data analytics in an apparel sector organization. The three contexts of the Technology-Organization-Environment (TOE) framework along with Technology Acceptance Model (TAM) were used as foundational frameworks to explore the influence on the attitude towards using of users which would ultimately affect to the intention of adopting big data analytics. The findings generated from the study denotes that factors considered in both TOE framework and TAM model except organizational context having a positive correlation towards the user's attitude of using which would ultimately lead the organization in enhancing its intention to adopt big data analytics. Finally, the research concludes that the variable, attitude towards using plays a positive mediating role between the direct relationship of critical factors affecting the intention to adopt big data analytics. It is hoped that findings of this research would enrich the existing literature while affecting practitioners to involve in adopting big data analytics by prioritizing investments accordingly.
\end{abstract}

Keywords-Critical factors; TOE framework; Technology Acceptance Model (TAM); attitude towards using; intention to adopt; Big Data Analytics (BDA); apparel sector; Sri Lanka

\section{INTRODUCTION}

The evolution of the concept, big data has occurred and expecting it to occur in future to develop more and more new and powerful computational technologies to respond and exploit the various types of data stored in the vast repositories which is continuing to accumulate data at a non-stop rate [1]. Hitt and Kim [2] have concluded that organizations which have already accepted the data-driven decision-making patterns and adopted accordingly, were able to enhance their productivity rates by $5-6 \%$. Since it has been several years from the introduction of big data analytics to the corporate world, still the majority of the industries operate at an early stage of adoption [3], while the rest struggle in the dark seeking for the ways to fully understand the functions and capabilities of the concept, big data [4]. Many research papers on this trending area depict a variety of influencing factors which would impact the intention of adopting big data and would go beyond merely focusing on the end user acceptance. When comes to Sri Lankan context, there is a dearth of studies which identifies the key potential factors affecting the organizations to develop an environment for big data analytics. To address the research gap, this paper grounded in Technology-OrganizationEnvironment (TOE) framework of Tornatzky and Fleischer [5], in combination with the Technology Acceptance Model (TAM) seeking to legend greater clarity on the critical factors that would influence big data adoption to broaden the knowledge and to assist the Sri Lankan apparel sector organizations with the adoption of big data in deriving towards the competitive advantage over its rivals which exist both within and outside the territory.

The remainder of this article proceeds as follows. Section II elaborates the research problem. Section III depicts the theoretical background. Significance of the study is discussed under Section IV and Section V covers the research design and methods. Section VI focuses on the analysis and discussion. Section VII concludes the overall idea of the study while final section pointing out the limitations of the study and the future research directions where further research could be carried out.

\section{RESEARCH PROBLEM}

In Sri Lanka, the apparel industry is known to be among the largest contributors to economic growth with a contribution over $\$ 5$ billion to gross domestic production which also accompanies a labour force of over 500,000. The Joint Apparel Association Forum (JAAF) is sharing a strongly confident view that the industry inherits a continuous potential to grow in spite of the rapidly evolving and increasing competition which the global market for apparel is subjected to [6]. Neighbour nations of Sri Lanka in the South Asian region are much bigger and expanding their industries while Sri Lanka are yet to make greater strides to face the competition [7].

The real challenge is to be competitive and yet increase significantly the share of value and volume in the market [7]. Speaking about the radical state of uncertainty around the globe, there is heightened demand for volatility, geopolitical risks, natural disasters, terrorist attacks, social media disruptions which are all taking their toll on global supply chains [7]. The changes are inevitable and will disrupt the textile supply chains [7]. The present circumstance of the Sri Lanka's apparel industry doesn't sound performing at a good rate due to COVID-19 pandemic crippling over the key customers which has led increased cancellation of orders which is a massive blow to the industry [8]. Brandix CEO [8] predicted about the possibility of a price war once the demand shrinks as the biggest player, obviously China working well 
along with semi lockdown of Bangladesh and with the work of both Vietnam and Indonesia which will have a direct impact to the Sri Lanka's positioning among the other apparel export markets.

The world is on the verge of a change and this change will have implications on the way Sri Lanka does business in the future and the ways, in which Sri Lankan apparel players design, source, manufacture and deliver, must be redesigned, if they truly need to keep the textile industry alive [7]. Therefore Sri Lanka needs to create a knowledge hub with emerging technologies and innovations such as artificial intelligence and advancements in material science coupled with digitalization, big data and analytics to create the perfect platform for modern day business [7].

When looking at the Sri Lankan context, a limited number of studies can be found and Premaratne [9] has analyzed the Sri Lankan lifestyles in data mining in the contexts of education and health. This indicates that the existing literature lacks the sufficient power to conduct quantitative evaluations and to identify and analyze the relationships among the influencing factors. The focus of the study is to identify the critical factors which influence the attitude of using big data analytics and the effect of them on the intention to adopt by an apparel sector organization. Therefore, the research questions of this study are:

- What determinants are responsible for explaining the variation of attitude towards using big data analytics and the weight of each determinant?

- To what extent is the attitude towards using big data analytics affecting the intention to adopt big data analytics?

- Is there a mediation effect of attitude towards using on the direct relationship between critical factors and the intention to adopt of big data analytics?

To address the highlighted research gap, this study specifically focuses on three research objectives as mentioned below:

- To explore the key determinants responsible for explaining the variation of attitude towards using big data analytics and to calculate the weight of each factor

- To examine the relationship between the variables; the attitude towards using big data analytics and the intention to adopt big data analytics

- To assess the mediation effect of attitude towards using on the direct relationship between critical factors and the intention to adopt big data analytics

\section{THEORETICAL BACKGROUND}

\section{A. Definition of Big Data}

A definition which was proposed by Gartner [10], defined big data as "high-volume, high-velocity and high-variety information assets that demand cost-effective, innovative forms of information processing for enhanced insight and decision making”. Lukoianova \& Rubin [11] further improved the definition by emphasizing the feature, veracity which refers to the accuracy of big data.

\section{B. The Technology-Organization-Environment (TOE) Framework}

Tornatzky \& Fleischer [5], framed the factors that could impact an organization in embracing innovation or technology were falling under three contexts known as technological (existing and new technologies), organizational (organization size, scope, managerial structure) and environmental (industry competitors, industry size, regulatory environment).

\section{1) Technological Context}

- Data-related Infrastructure Capabilities

An organization's readiness and the ability of using big data analytics will be reflected by the extent to which the organization has better infrastructure capabilities and also the integration of underlying data which is required by the supportive data infrastructures can be considered as one of the complex undertakings [12].

\section{- Data Management}

Data needs to fulfil the main fundamentals such as reliability, completeness, timeliness, consistency and accuracy for its usage and consumption within the big data analytics domain [13], [14] \& [15]. Unless the fundamentals in data are not achieved, usage of data analytics will be hampered and limited as the trust in data will be lost by the users and as well by decision makers [16].

\section{- Privacy \& Security}

Big data also known to be changing the landscape of security technologies towards networking and forensics and in circumstances where there are no right security and encryption, then it leads to serious threats from big data [17]. If the intelligence of the assaulter is far beyond the installed security limits, then the encryption techniques wouldn't be sufficient either to defend or to shield the log files [18].

\section{2) Organizational Context}

- Vision and Strategy

An initiative regarding to big data analytics should pop up based on the business requirements and therefore, to direct the implementation, it needs to be backed by a strategic business vision [19]. If not, the big analytics systems are business centric, it will lead to failure. Always there needs to be a business problem to generate positive results from big data analytics.

\section{- Sponsorship and Governance}

Watson et al., [20] emphasized the necessity to receive the consistent support and sponsorship from business executives in securing the operating resources required throughout the implementation process. He [20] also pointed out this as a mostly expected outcome as a significant cost, time and many other resources required to be invested throughout the process and to bring it to alive.

\section{- Organizational Structure}


Shiwei, et al., [4] emphasized that the well-built organized structure of an organization has been supportive to the adoption of big data such as cross-organizational collaboration structure, data analytics departments and staff configurations.

\section{- Talent Strategy \& Capability Development}

This aspect focuses on the highly skilled and experienced people which are vital requirements for the analytical transformation of the organization and for the need of industrialized individual analytical capabilities to move up on the ladder of analytical maturity scale.

\section{- Firm Size}

Size of a firm can be measured from different aspects such as annual revenue generated and number of employees employed, which would enhance the level of adoption of big data opening more avenues for organizations to enhance its position in terms of revenue. However, the existing literature indicates that there is no precise direction as some articles depicts a positive relationship [21], [22], [23], while others speak about a negative correlation [24], [25] \& [26].

\section{3) Environmental Context}

- Market Pressure

Masrek, et al., [27] suggested that it is unavoidable for organizations to face competitive pressures and environment uncertainties, and it has persuaded them to engage in greater sensing and search activities to understand both the internal and the external environments of an organization through strategic initiatives such big data analytics.

\section{- Big Data Pressure}

Agrawal [28], has mentioned that big data adoption consists of two main constructs and they are the perceived competition intensity to implement big data adoption and also the risk of competitive disadvantage arises due to the inability in adopting big data analytics.

\section{Technology Acceptance Model (TAM)}

This study seeks the application of TAM model to observe the user attitude towards big data analytics as it satisfactorily determines how the user perceives the ease of using and as well as the usefulness of the new system which is going to be implemented [29].

\section{1) Perceived Usefulness}

A system which bears the status of high perceived usefulness, in turn is one for which user believes that there exists a positive relationship of performance in use [29]. According to Guriting and Ndubisi [30] and Eriksson et al., [31], usefulness is the subjective probability that how it will enhance the efficiency and effectiveness of the way the user supposes to complete a given task using the technology.

\section{2) Perceived Ease of Use}

This refers to the degree to which believes that a user has on using a certain system would be free from difficulties and great efforts [29]. Some researchers argued that perceived ease of use could be suggested as to the extent to which the user accepts that the use of an exacting method would be free from adding a single cost to that individual and the extent of reality of that view [29] \& [32].

\section{Attitude Towards using}

Currently, the role performed by the affective attitudes remains as an open issue which needs to be attended [29]. At first, Lancaster [33] pointed that attitude can be introduced as the driver for utility or attributes while Triandis [34] described attitude as the perception of an individual where he/she is either positive or negative towards the innovation adoptions.

\section{E. Intention to Adopt Big Data Analytics}

Through this concept, a predefined future behavior is expected to achieve [35] and it is known to be a key predictor when comes to the assessment of an individual's actual use of technology [36] \& [37]. Muhammad, et al., [38] emphasized that the actual use of BDA (Big Data Analytics) in a given organization would depend on the number of individuals positive towards the intention of using BDA.

\section{SigNIFICANCE OF THE STUDY}

\section{A. Theoretical Significance}

It is believed that this study would contribute with noteworthy research insights when comes to the assessment of the intention to adopt BDA in apparel sector, Sri Lanka and also expects that findings which have arrived with, would bridge the main gap in the literature concerning the empirical evidences for the intention to adopt BDA among Sri Lankan apparel sector organizations for the first time. Secondly, the majority of the existing literature supports the research insights of importance, challenges, and opportunities of BDA, as it has been the initial stage of BDA and it was comparatively a new concept [39]. The integration of two technology adoption frameworks (TAM model \& TOE framework) would involve in providing the most relevant academic insights with an expanded research model in exploring the intention to adopt BDA and this could be treated as a remarkable point which would enhance the existing literature. Finally, once the investigation is completed, the research will give an idea regarding the factors mainly influence on the user intention to adopt BDA with the mediating effect of attitude towards using and the generated the results would provide the opportunity to reference the findings in the future research and to enhance the understanding of the adoption of BDA.

\section{B. Practical Significance}

This study is designed to contribute practically in several ways like theoretical contributions. It is expected that the findings will propose most important guidelines and implications for both practitioners and implementers of big data analytics systems which will ultimately affect to the successful adoption of big data analytics systems in the organizations. Bringing out the connectivity of system with the functions and required tasks along with facilitating the perceived usefulness and perceived ease of use of the system are vital to an organization [39]. This approach will further emphasize the importance of the results that are more fruitful for practitioners when implementing big data analytics systems in developing countries as the findings are based in a developing country which falls under the continent, Asia. 
Finally, it is possible to consider that the results of the study will create an initial platform for adopting and promoting big data practices to obtain maximum advantages of innovation technologies in the context of developing countries.

\section{RESEARCh DESIGN AND Methods}

\section{A. Research Approach}

This research will be based on positivistic paradigm where new knowledge could be discovered through objective measures. In order to achieve the research objectives, quantitative research methodology is primarily used. This study mainly focuses on identifying the relationships between factors such as technological, organizational and environmental factors, perceived usefulness, perceived ease of use and the intention to adopt big data analytics with the mediating effect of attitude towards using. Through using the positivism approach, the study gives the possibility in identifying the sorts of relationships between the independent and dependent variables exist. The approach using, is justifiable as it tries to determine a causal relationship between the variables tested, to generalize to a larger group of individuals than those who are participating in the investigation and to understand behavioral patterns and the reasons behind that behavior. Therefore, the dominance strategy for this study could be identified as positivism.

\section{B. Population and Study Sample}

The sampling frame that is considered to test hypothesis are the 13 key players in the Sri Lankan Apparel sector as disclosed in the "Industry Capability Report - Sri Lankan Apparel Sector” by Export Development Board, Sri Lanka in January 2020. The study mainly focuses on assessing the level of acceptance of BDA by employees who belong to the category of executive and above, among the key players in Apparel sector. When considering the key 13 players, it approximately caters an employee base of 7,844 who are performing with in the category of executive and above, in the Sri Lankan territory. As the key 13 players are also having operations outside of Sri Lankan territory (overseas), those were not taken to the scope of Sri Lanka as those apparel exports will not get into the count of Export Development Board of Sri Lanka and as well as, the natives in those locations will mainly be used for the operations.

The approximate target population of 7,844 employee base spreads across the 13 key players as Mas Intimates (Pvt) Ltd 25\%, MAS Active Trading (Pvt) Ltd - 14\% and Bodyline (Pvt) Ltd - 10\%, EAM Maliban Textiles Mahiyanganaya (Pvt.) Ltd 7\%, Jay Jay Mills Lanka (Pvt) Ltd - 7\%, Linea Aqua (Pvt) Ltd - 6\%, Polytex Garments Ltd - 6\%, Brandix Apparel Ltd - 5\%, Smart Shirts Lanka Ltd - 5\%, Orit Trading Lanka (Pvt) Ltd 5\%, Hirdaramani International Exports Ltd - 4\%, Courtaulds Trading Co (Pvt.) Ltd $-4 \%$ and Omega Line Ltd - 2\% respectively.
Out of the total population, randomly 365 individuals were selected on a pro-rata basis among the 13 key players to generate conclusions about the entire population.

\section{Conceptual Framework}

Based on the above information, this study mainly focuses on investigating whether attitude towards using, mediating the relationship between the independent variables; perceived usefulness, perceived ease of use, technological factors, organizational factors, environmental factors, and the dependent variable; intention to adopt BDA. This can be graphically presented as shown in Fig. 1 and from the diagram itself, two dependent variables can be identified as "Attitude towards using" and "Intention to adopt big data analytics". Out of those two dependent variables, the dependent variable, "Attitude towards using” plays a role of a mediating variable which will be assessed in the next section.

\section{Hypothesis}

H1: Data-related infrastructure capabilities will positively influence attitude towards using big data analytics.

H2: Data management will positively influence attitude towards using big data analytics.

H3: Privacy \& security will positively influence attitude towards using big data analytics.

H4: Vision and strategy will positively influence attitude towards using big data analytics.

H5: Sponsorship and governance will positively influence attitude towards using big data analytics.

H6: Well established organizational structure will positively influence attitude towards using big data analytics.

H7: Talent strategy \& capability development will positively influence attitude towards using big data analytics.

H8: Firm size will positively influence attitude towards using big data analytics.

H9: Market pressure will positively influence attitude towards using big data analytics.

H10: Big data pressure will positively influence attitude towards using big data analytics.

H11: Perceived usefulness will positively influence attitude towards using big data analytics.

H12: Perceived ease of use will positively influence attitude towards using big data analytics.

H13: Attitude towards using big data analytics will positively influence the intention to adopt big data analytics. 


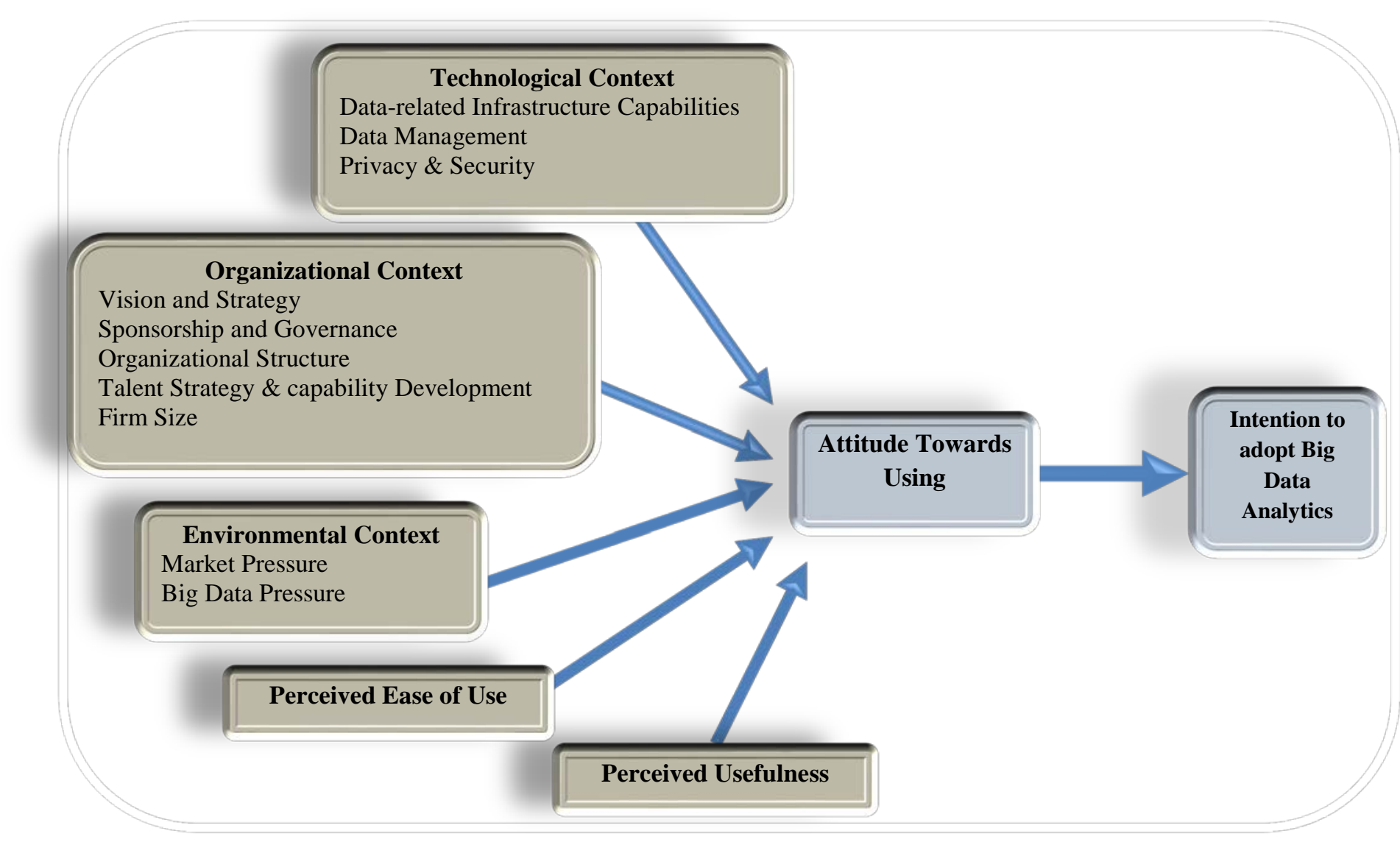

Fig 1. Research Model - (Author Constructed).

\section{E. Source of Data}

The only source of data collection considered under this study is the questionnaire developed using the current literature written about BDA. Therefore, the research has been carried out using primary source of data.

\section{F. Instrumentation}

In order to refine the survey tool; the questionnaire, expert opinion was obtained from both academic and industry experts and a pilot survey was initially done to check the applicability of the questions. The questionnaire consisted of two parts as mentioned below.

Part 1 consists of questions relating to demographics of the participants of the survey such as age, gender, employed function/department, employment tenure, level of employment, level of education and employed organization.

Part 2 comprises of questions which examine factors affecting the intention to adopt BDA and questions which assess the mediating effect of attitude towards using in the relationship between main determinants and intention to adopt BDA.

In the case of quantification of the content in the part 2 of the questionnaire, each sub variable is given a score within the range of 1 and 5, based on Likert scale (Table I) which was also used by Anke Schull and Natalia Maslan [40] in 2018.
TABLE I. LIKERT SCALE (1-5)

\begin{tabular}{|l|l|}
\hline Scale & Criteria \\
\hline 1 & Strongly Disagree \\
\hline 2 & Disagree \\
\hline 3 & Neutral \\
\hline 4 & Agree \\
\hline 5 & Strongly Agree \\
\hline
\end{tabular}

\section{G. Collection of Data}

Data with respect to the phenomenon; intention to adopt BDA in apparel sector of Sri Lanka, was collected in selecting individuals on random basis with the help of a survey questionnaire. Questionnaires were distributed among the sample selected using an online method. The current literature was gathered to support the information collected through the questionnaire.

\section{H. Data Analysis Strategies with Justification}

Data which was gathered through sharing a questionnaire among the selected individuals in 13 key players in the apparel sector was analyzed using IBM Statistical Package of Social Sciences (SPSS 23). In this case, techniques such as descriptive and inferential statistics were mainly used for describing and analyzing the collected data. 
When comes to the further analysis of data, measures of central tendency such as mean, median and mode fall under descriptive statistics and measures such as regression and correlation analysis to assess the nature of relationships exist among the variables fall under inferential statistics were computed.

Following data analysis strategies were used when analyzing the data to assess whether the main objectives of the research achieved or not.

- To explore the determinants responsible for explaining the variation of attitude towards using big data analytics - Regression and Correlation Analysis.

- To identify the key influencing factors for the adoption of big data by organizations in apparel sector of Sri Lanka and to calculate the weight of each factor Measures of Central Tendency.

- To examine the relationship among the variables; the attitude towards using big data analytics and the intention to adopt big data analytics - Regression and Correlation Analysis.

- To assess the mediation effect of attitude towards using on the direct relationship between critical factors and the intention to adopt of big data analytics - SobelGoodman Test.

\section{ANALYSIS AND DISCUSSION}

Initially, this section explains the sample overview. Then it depicts the results of the descriptive statistics in measuring the critical factors responsible for the behavior of the variable, attitude towards using BDA. Next, correlation analysis and multivariate regression analysis are performed to identify the relationships among the chosen variables/ determinants responsible for explaining the variation of attitude towards using BDA and the extent to which the attitude towards using BDA affecting the intention to adopt BDA. It will be followed by the multicollinearity testing to investigate whether there is a correlation among independent variables that would affect the regression results achieved. Further, to assess the mediating effect of attitude towards using on the direct relationship between critical factors and the intention to adopt of BDA, Sobel-Goodman test is used. Finally, the section is concluded with a brief summary of the results of the analysis performed.

\section{A. Sample Overview}

According to the Joint Apparel Association Forum (JAAF), Sri Lanka has already able to keep a record of 5.3 billion USD from apparel exports in 2019 while contributing 6\% and 40\% to Sri Lanka's GDP (Gross Domestic Production) and country's total exports respectively [41]. The behavior of the top 10 players in the apparel sector over a period of 7 years is graphically presented in the Fig. 2 and it highlights the apparel manufacturers; Brandix Apparel Limited, MAS Intimates (Pvt) Ltd, MAS Active Trading (Pvt) Ltd and Hirdaramani International Exports Ltd have operated above the annual revenue of USD 0.3 billion from 2014 onwards. In addition, MAS Holdings and Brandix Lanka have been nominated for ranking 1 and 2 with a score of 90.18 and 89.28 respectively in Export Corporate Brands 2020 [42].

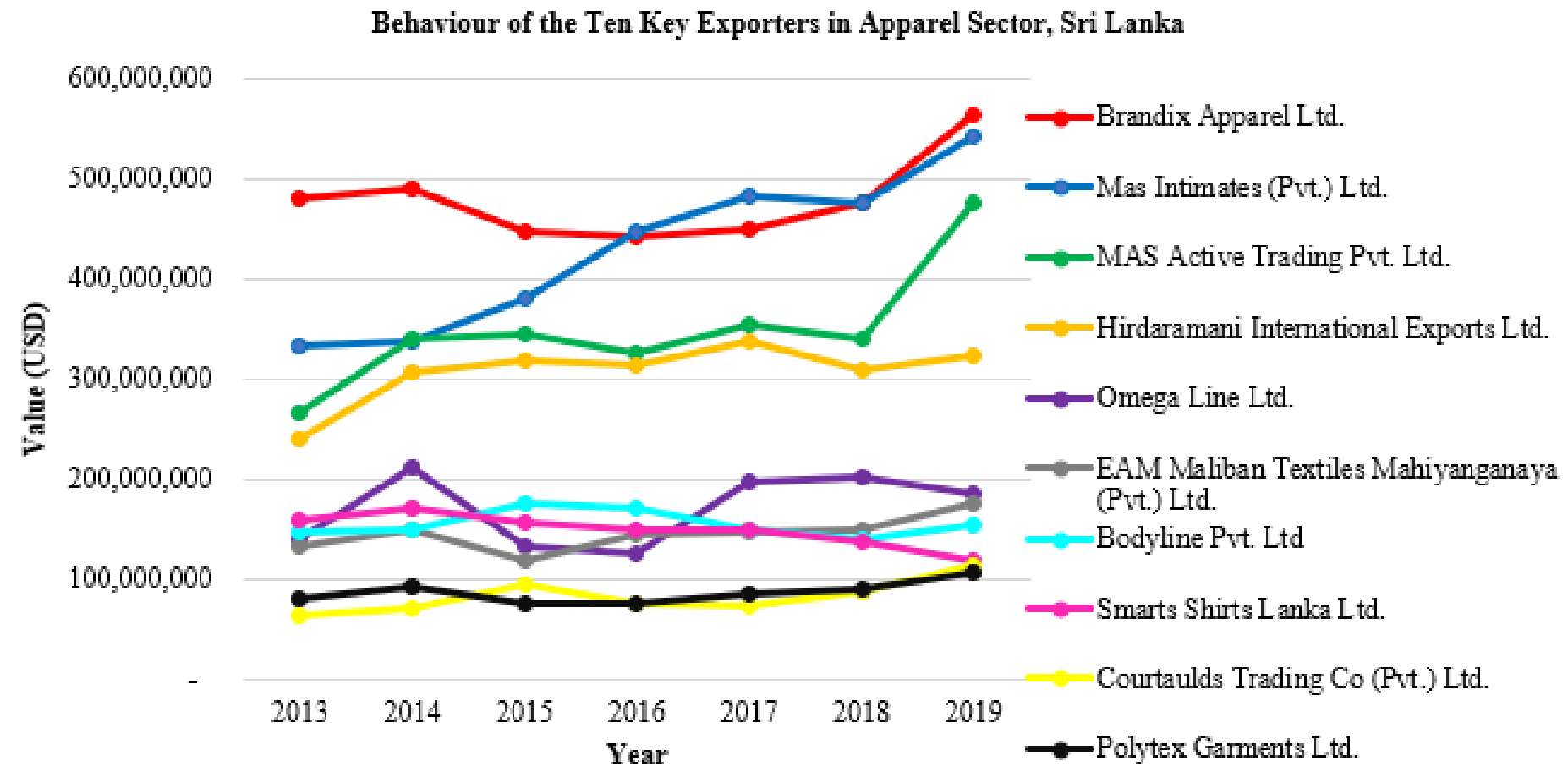

Fig 2. Sri Lanka Apparel Exports - (Board of Investments, Sri Lanka). 


\section{B. Demographics}

The information reveals that majority of respondents represent the gender, male (60.8\%) while female is $39.2 \%$. When comes to the age, most of the participants are between 26 to 30 years (53.7\%), with $18.9 \%$ from 31 to $35,12.1 \%$ from 22 to $25,9.3 \%$ from 36 to $40,5.5 \%$ from 41 to 50 with a low minority (0.5\%) above 50. Almost equal number of participants is shared among the functions finance (20.5\%) and marketing (20\%) while the rest are from operations $(15.3 \%)$, human resources $(9.6 \%)$, supply chain $(8.8 \%)$, engineering (7.4\%), information technology (6\%), administration (2.2\%), data analytics and other departments under general management falling into $10.1 \%$. As per the work experience (tenure), majority represent 2 to 4 years (44.9\%) while $22.7 \%$ was from more than 5 years, $14.2 \%$ from 4 to 5 years, $12.1 \%$ from 1 to 2 years and $6 \%$ from less than 1 year. In terms of the roles perform in the given organizations, majority of the participants represents the executive level (45.5\%) whereas the rest were from senior executives (21.4\%), manager (14.5\%), assistant manager (11\%), general-manager (2.5\%) and with a low minority from director, CXO \& consultant (0.9\%). Finally arriving at the last demographic variable; education, it denotes that the majority hold a bachelor's degree (53.2\%), while $36.2 \%$ consists with master's degree, $6.3 \%$ has learnt up to high school and $4.4 \%$ holds a professional school degree/certificate.

\section{Validity and Reliability}

A reliability assessment was done using Cronbach Alpha. For all variables; technological (0.879), organizational (0.913), environmental (0.890), perceived ease of use (0.908), perceived usefulness (0.933), attitude towards using (0.921) and intention to adopt (0.929), Cronbach's alpha coefficients showed a high level of reliability, ranging from 0.879 to 0.933 , with a highest satisfactory value for the variable, intention to adopt BDA. The Kaiser-Meyer-Olkin (KMO) measure of sampling adequacy for all variables was above 0.8 implied the adequacy of the sample and Bartlett's test of sphericity denoted the significance of each construct.

\section{Descriptive Statistics}

The generated descriptive statistics reveal that the mean value of the technological context amounts to a value of 4.136 with a median value of 4.2 while the standard deviation is 0.648 (15.6\% of the mean value). The second independent variable, organizational context presents a mean and a median of 3.790 and 4.000 respectively while with a standard deviation of 0.623 (16.4\% of the mean value). The third independent variable, environmental context denotes a mean value of 4.103 with a medium value of 4.2 . It also consists with a standard deviation of 0.682 ( $16.6 \%$ of the mean value). Collected data also emphasizes a mean of 3.865 and a median of 4.2 along with the standard deviation of 0.793 which is $20.5 \%$ of mean value for the next independent variable, perceived ease of use. The final independent variable, perceived usefulness denotes a mean of value of 3.966 and a median value of 4.2 with a standard deviation of 0.792 (19.9\% of the mean value). The collected data derives with a mean value of 4.037 and a median value of 4.166 along with a standard deviation of $0.706(17.4 \%$ of the mean value) for the mediating variable, attitude towards using. Finally, the dependent variable, intention to adopt BDA denotes a mean value of 3.932 while the median value would be 4.166. The standard deviation of this dependent variable is 0.764 which is $19.4 \%$ of the mean value.

\section{E. Regression Analysis}

In this study, we examine the relationships among technological context, organizational context, environmental context, perceived ease of use, perceived usefulness, attitude towards using and intention to adopt BDA and $\mathrm{R}^{2}$ and t-tests are used to identify the coefficients and relationships among variables.

1) Regression Analysis of Technological Context vs. Attitude Towards Using

In the testing of goodness of fit, technological context elucidates $\mathrm{R}^{2}$ value of 0.533 on attitude towards using, which depicts an explanatory capability of $53.3 \%$, along with a pvalue of 0.000 less than 0.05 , indicating that the attitude towards using is significantly and proportionally affected by the technological context. The coefficient is 0.730 , which means that when increasing the technological context by one unit, the attitude towards using will increase by 0.730 units.

2) Regression Analysis of Organizational Context vs. Attitude Towards Using

Organizational context explains a $\mathrm{R}^{2}$ value of 0.360 of attitude towards using which is having a considerable level of an explanatory power on the dependent variable as it explains $36 \%$. The significance level which is below 0.05 reflects the variable; attitude towards of using will significantly be affected by the organizational context built in. The coefficient of 0.600 explains that if organizational context increases by 1 unit, then the attitude towards using will enhance by 0.600 units.

3) Regression Analysis of Environmental Context vs. Attitude Towards Using

$\mathrm{R}^{2}$ value of 0.581 along with the $\mathrm{p}$-value less than 0.05 reflect the significant explanatory power of the independent variable; environmental context over the dependent variable attitude towards using and this relationship further proved by the generated positive t-value. The coefficient 0.762 denotes if 1 unit of environmental context is enhanced, then it will lead to 0.762 units enhancement of attitude towards using.

4) Regression Analysis of Perceived Ease of Use vs. Attitude Towards Using

The relationship between perceived ease of use and attitude towards using generates a $\mathrm{R}^{2}$ value of 0.543 which highlights that the $54.3 \%$ of attitude towards using is decided by perceived ease of use. The high explanatory power of this relationship is further confirmed by the p-value which is less than 0.05 and by the positive t-value. The coefficient value of 0.737 denotes if 1 unit of perceived ease of use is increased, it will lead to 0.737 units increase in attitude towards using.

5) Regression Analysis of Perceived Usefulness vs. Attitude Towards Using

The independent variable, perceived usefulness will decide the behavior of the Variable, attitude towards using by $62.2 \%$ as the regression statistic derives a $R^{2}$ value of 0.622 . The power of explanation on the dependent variable, attitude 
towards using will be further strengthen by positive t-value generated along with a significance value of less than 0.05 . The coefficient value of 0.789 reflects that if 1 unit of perceived usefulness is enhanced, it will lead to the enhancement of 0.789 units of attitude towards using.

6) Regression Analysis of Attitude towards using vs. Intention to Adopt Big Data Analytics

In this context, $\mathrm{R}^{2}$ value of 0.639 denotes that $63.9 \%$ of the dependent variable is decided by the variable, attitude towards using. This relationship is further proved by positive t-value generated and the p-value which is below 0.05 . The coefficient of 0.799 emphasizes that if 1 unit of attitude towards using is enhanced, it has the capability of increasing the dependent variable, intention to adopt BDA by 0.799 units.

7) Multiple Regression Analysis of Critical factors; Technological Context, Organizational Context, Environment Context, Perceived Ease of use and Perceived Usefulness vs. Attitude Towards Using
In the testing of goodness of fit, the technological context, organizational context, environmental context, perceived ease of use and perceived usefulness would be elucidating $\mathrm{R}^{2}$ value of 0.735 of attitude towards using, which is having an explanatory power of $73.5 \%$. The p-values of technological context, environmental context, perceived ease of use and perceived usefulness are lesser than 0.05 which have reached the significance level and the positive $t$ values emphasize that attitude towards using would be significantly and proportionally affected by those independent variables.

However, the independent variable, organizational context shares a negative coefficient value of 0.091 along with a $\mathrm{p}$ value of 0.033 . As the significance is below 0.05 , it denotes that the variable, attitude towards using is known to be dependent on the independent variable, organizational context but the generated data doesn't have enough power to detect that dependence.

TABLE II. CRITICAL FACTORS Vs. ATtITUDE TOWARDS Using

\begin{tabular}{|c|c|c|c|c|c|c|c|}
\hline \multirow{2}{*}{ Model } & \multicolumn{2}{|c|}{ Unstandardized Coefficients } & \multirow{2}{*}{$\begin{array}{l}\text { Standard Coefficients } \\
\text { Beta }\end{array}$} & \multirow{2}{*}{$t$} & \multirow{2}{*}{ Sig. } & \multicolumn{2}{|c|}{ Collinearity Statistics } \\
\hline & B & Std. Error & & & & Tolerance & VIF \\
\hline (Constant) & 0.382 & 0.134 & & 2.851 & 0.005 & & \\
\hline Technological Context & 0.204 & 0.052 & 0.187 & 3.935 & 0.000 & 0.327 & 3.061 \\
\hline Organizational Context & -0.103 & 0.048 & -0.091 & -2.135 & 0.033 & 0.409 & 2.443 \\
\hline Environmental Context & 0.309 & 0.049 & 0.299 & 6.313 & 0.000 & 0.331 & 3.024 \\
\hline Perceived Ease of Use & 0.186 & 0.043 & 0.209 & 4.290 & 0.000 & 0.312 & 3.203 \\
\hline Perceived Usefulness & 0.306 & 0.043 & 0.343 & 7.095 & 0.000 & 0.316 & 3.166 \\
\hline
\end{tabular}

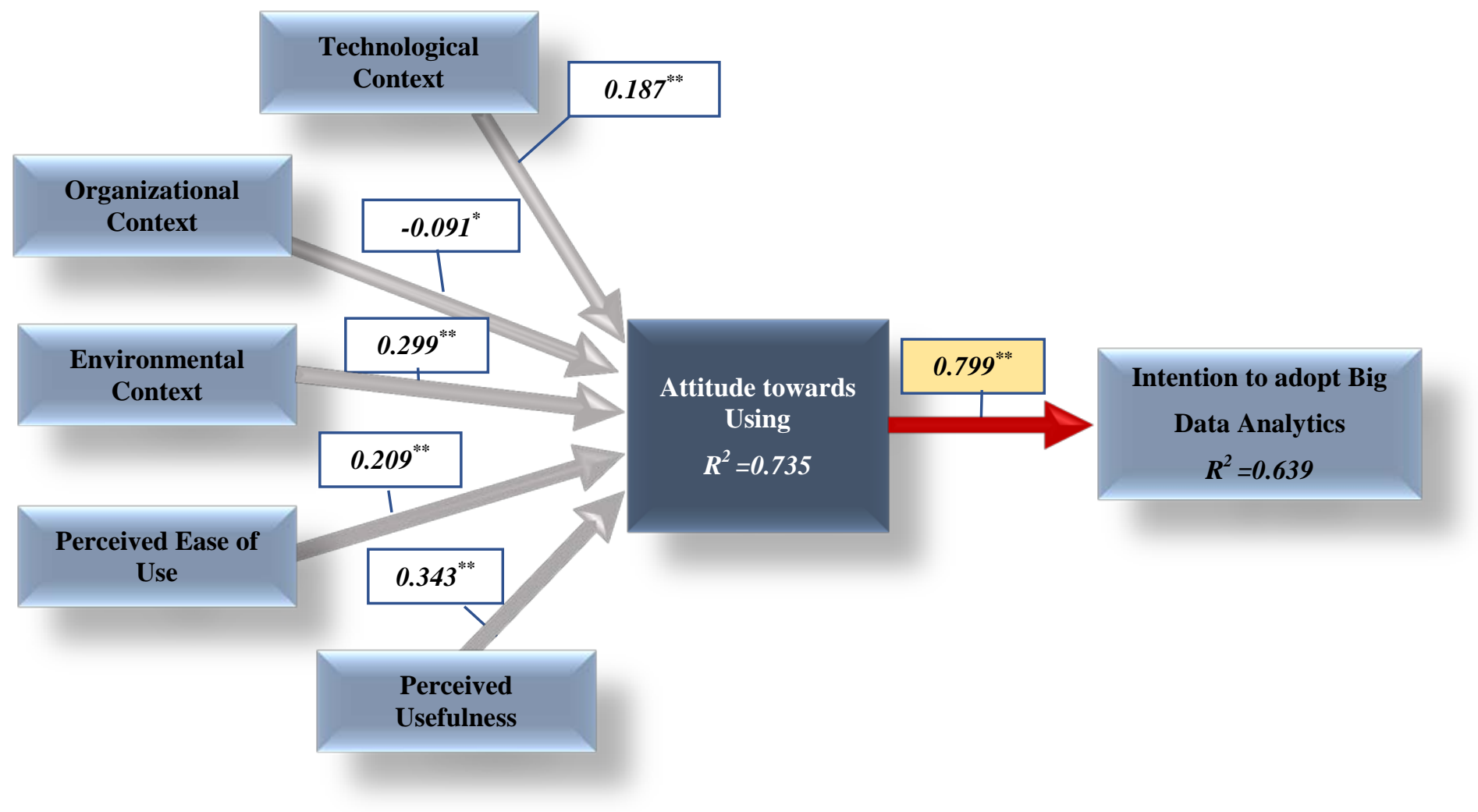

Fig 3. Research Results $\left({ }^{*} \mathrm{p}<0.05,{ }^{* *} \mathrm{p}<0.01\right)$. 
The coefficients of technological context (0.187), environmental context $(0.299)$, perceived ease of use $(0.209)$ and perceived usefulness (0.343) emphasize the stronger effect of those independent variables on the dependent variable, attitude towards using (Table II).

Summing up the above results, the regression results were graphically indicated in Fig. 3.

8) Multicollinearity among the Independent Variables

In this case to evaluate the multicollinearity effect of independent variables such as technological context, organizational context, environmental context, perceived ease of use and perceived usefulness, the statistical measurement; variance inflation factor (VIF) was used. Table II depicts the VIFs for all the independent variables in the model of this study which exist between 1 and 5 concluding an existence of a moderate correlation among the independent variables that emphasizes the strength of correlation between independent variables is not significant.

\section{F. Hypothesis Testing}

In this case, to test the proposed hypothesis, the results were interpreted using regression while taking into consideration the sample size. Table III will summarize the results.

\section{1) Data-Related Infrastructure Capabilities}

The results show a positive effect between data related infrastructure capabilities and the attitude of using BDA with a high significance level of lesser than 0.05 along with a positive t-value. This confirms enough evidences to reject the null hypothesis.

\section{2) Data Management}

The coefficient and p-value of $\mathrm{H} 2$ on the regression analysis are 0.711 and 0.000 (lesser than 0.05 ) which denote that there is a powerful positive relationship between data management and attitude towards using BDA. The hypothesis is further supported by positive t-value of 19.252. Researchers such as Malladi and Krishnan [43] and Kwon et al., [16] have also noted that how important it is to manage the challenges in data from both internal and external sources for BDA usage.

\section{3) Privacy and Security}

Privacy and security regarding data is having a coefficient of 0.542 which is strengthened by a p-value of less than 0.05 and a positive t-value. Therefore, the statistics support $\mathrm{H} 3$ and Gangwar [44] has also emphasized that the increase of privacy and security concerns will have a significant negative effect on big data adoption.

\section{4) Vision and Strategy}

The regression analysis for vision and strategy vs. attitude towards using BDA gave a p-value of 0.000 (lesser than 0.05 ) and a t-value of 13.935 which would the support the acceptance of H4. Therefore, the statistics results emphasize that a strategic business vision is most essential to make a change the way users think and to direct the BDA implementation effort.

\section{5) Sponsorship and Governance}

Sponsorship and governance are having a positive coefficient of 0.554 towards the attitude of using BDA. The positive relationship between these two variables is further confirmed by the p-value below 0.05 and the positive t-value of 12.687. Therefore, H5 hypothesis can be accepted and it highlights that user will never have a positive attitude unless it is backed by commitment of top management with a proper funding and governance mechanism.

\section{6) Organizational Structure}

Positive t-value of 11.981 and p-value of 0.000 which is lesser than 0.05 support the hypothesis which emphasizes that well established organizational structure will positively influence the attitude towards using BDA. These results indicate that organizational structure seems also affecting the user attitude towards BDA and Shiwei, et al., [4], has revealed that he has come across 22 frequencies through content analysis where it has been mentioned, "organization has a well-organized structure that is well-suited to the adoption of big data”.

\section{7) Talent Strategy \& Capability Development}

The regression analysis of $\mathrm{H} 7$ gave a p-value of 0.000 which is lesser than 0.05 along with a t-value of 13.562 . It can thus be concluded that the null hypothesis for $\mathrm{H} 7$ should be rejected and that talent strategy \& capability development have a positive effect on the users' attitude towards using BDA. This is further supported by Schüll \& Maslan [40] mentioning a focus needs to be given on the skill development, when channeling the investments on BDA.

\section{8) Firm Size}

The regression analysis of $\mathrm{H} 8$ gives a p-value of 0.821 and therefore the null hypothesis is accepted, and $\mathrm{H} 8$ is not supported. It can be inferred that firm size does not influence the attitude towards using BDA. The findings of Gangwar [44], depicted that the firm size was playing a statistically significant role, but also emphasized that there wasn't exact size-fit relationship when comes to the organizational size and the adoption rate of big data.

\section{9) Market Pressure}

The effect of market influence on users' attitude of using BDA is positive and the hypothesis H9 is supported with a regression analysis giving a p-value of 0.000 . Therefore, market pressure does have a positive as well a significant influence towards the users' attitudes of adopting BDA and this is further proven by, Lautenbach, et al., [45] agreeing with the view that $\mathrm{BDA}$ enables the organizations to gain competitive advantage over its rivals.

\section{0)Big Data Pressure}

The regression analysis of $\mathrm{H} 10$ gave a p-value of 0.000 and as a result, null hypothesis could be rejected. Therefore, it can be inferred that big data pressure does have a positive and a significant influence on the attitude towards using BDA.

Finally, hypothesis testing can be concluded with the hypotheses, H11, H12, H13 which have the highest positive influences which are confirmed by the positive r-values achieved as $0.789,0.737$ and 0.799 respectively. These positive influences can be nominated as significant relationships as the statistics derive positive t-values and p-values of 0.000 (less than 0.01) for all those hypotheses and all of them can be accepted while rejecting the null hypotheses (Table III). 
TABLE III. HYPOTHESIS SUMMARY

\begin{tabular}{|c|c|c|c|c|}
\hline Hypothesis & $r$ value & $t$ value & $p$ value & Indicator \\
\hline $\begin{array}{l}\text { H1: Data-related infrastructure capabilities will positively influence attitude } \\
\text { towards using big data analytics. }\end{array}$ & 0.646 & 16.143 & 0.000 & Supported \\
\hline $\begin{array}{l}\text { H2: Data management will positively influence attitude towards using big data } \\
\text { analytics. }\end{array}$ & 0.711 & 19.252 & 0.000 & Supported \\
\hline $\begin{array}{l}\text { H3: Privacy \& security will positively influence attitude towards using big data } \\
\text { analytics. }\end{array}$ & 0.542 & 12.297 & 0.000 & Supported \\
\hline $\begin{array}{l}\text { H4: Vision and strategy will positively influence attitude towards using big data } \\
\text { analytics. }\end{array}$ & 0.590 & 13.935 & 0.000 & Supported \\
\hline $\begin{array}{l}\text { H5: Sponsorship and governance will positively influence attitude towards using } \\
\text { big data analytics. }\end{array}$ & 0.554 & 12.687 & 0.000 & Supported \\
\hline $\begin{array}{l}\text { H6: Well established organizational structure will positively influence attitude } \\
\text { towards using big data analytics. }\end{array}$ & 0.532 & 11.981 & 0.000 & Supported \\
\hline $\begin{array}{l}\text { H7: Talent Strategy \& capability Development will positively influence attitude } \\
\text { towards using big data analytics. }\end{array}$ & 0.580 & 13.562 & 0.000 & Supported \\
\hline H8: Firm size will positively influence attitude towards using big data analytics. & -0.012 & -0.227 & 0.821 & Not Supported \\
\hline $\begin{array}{l}\text { H9: Market pressure will positively influence attitude towards using big data } \\
\text { analytics. }\end{array}$ & 0.675 & 17.439 & 0.000 & Supported \\
\hline $\begin{array}{l}\text { H10: Big data pressure will positively influence attitude towards using big data } \\
\text { analytics. }\end{array}$ & 0.755 & 21.924 & 0.000 & Supported \\
\hline $\begin{array}{l}\text { H11: Perceived usefulness will positively influence attitude towards using big data } \\
\text { analytics. }\end{array}$ & 0.789 & 24.464 & 0.000 & Supported \\
\hline $\begin{array}{l}\text { H12: Perceived ease of use will positively influence attitude towards using big } \\
\text { data analytics. }\end{array}$ & 0.737 & 20.776 & 0.000 & Supported \\
\hline $\begin{array}{l}\text { H13: Attitude towards using big data analytics will positively influence the } \\
\text { intention to adopt big data analytics. }\end{array}$ & 0.799 & 25.344 & 0.000 & Supported \\
\hline $\begin{array}{l}\text { G. Mediating Effect of Attitude towards Using on the Direct } \\
\text { Relationship between Critical Factors and the Intention to } \\
\text { Adopt Big Data Analytics } \\
\text { To identify the mediating effect of attitude towards using }\end{array}$ & \multicolumn{4}{|c|}{$\begin{array}{l}\text { on the direct relationship between critical factor } \\
\text { (technological context, organizational context, environmenta } \\
\text { context, perceived ease of use and perceived usefulness) an } \\
\text { the intention to adopt BDA, Sobel-Goodman test wa } \\
\text { performed. }\end{array}$} \\
\hline
\end{tabular}

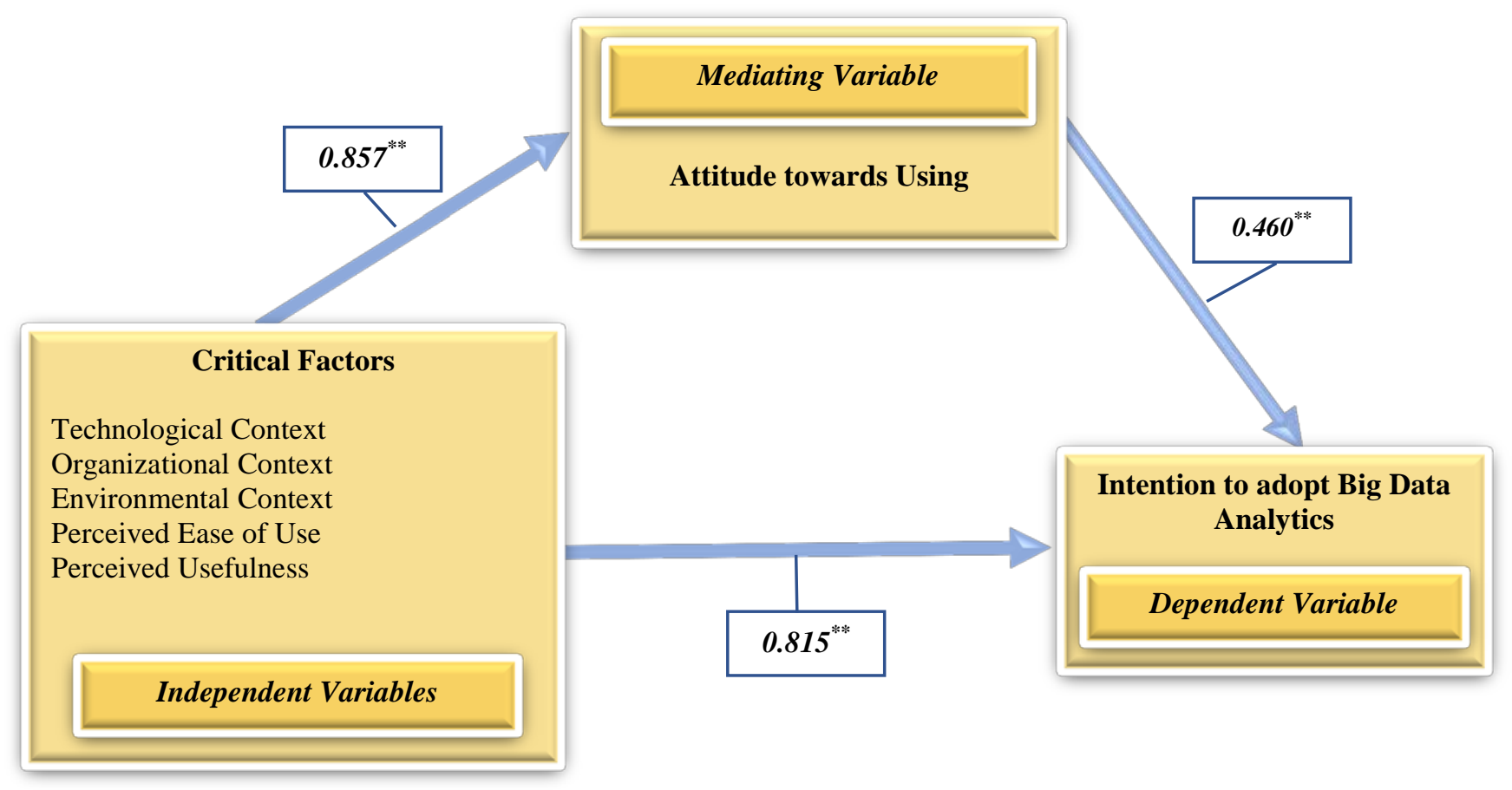

Fig 4. Research Results (Mediating Effect) $\left({ }^{*} \mathrm{p}<0.05,{ }^{* *} \mathrm{p}<0.01\right)$. 
TABLE IV. MEdiator Role OF AtTitude TOWARds Using

\begin{tabular}{|l|l|l|l|}
\hline Test Type & Test Statistic: & Std. Error & $\boldsymbol{p}$-value \\
\hline Sobel-Goodman test & 2.252 & 0.189 & 0.024 \\
\hline
\end{tabular}

As per the Fig. 4, the variable, "Attitude towards using" could be considered a mediator to the extent to which it carries the influence of the given independent variables, "Critical factors" to the given dependent variable, "Intention to adopt $B D A$ ”. Overall, fulfillment of four criteria will assure the existence of a mediating effect and those will be (1) when there is a significant influence on the variable, attitude towards using from the independent variables; critical factors, (2) in the absence of the variable, attitude towards using, if the critical factors cause a significant impact on the behavior of intention to adopt BDA, (3) the mediator, itself having a significant and as well as a unique effect on the dependent variable, intention to adopt BDA and (4) the final criteria that the significance of the influencing power of critical factors on the dependent variable, intention to adopt BDA will shrink upon the addition of the variable, attitude towards using as a mediator to the model [46]. The results depict the successful achievement of the specified four criteria which emphasizes the mediating role performs by the variable, attitude towards using BDA. However, MacKinnon \& Dwyer [47] have popularized statistically based methods by which mediation may be formally assessed. Table IV depicts the statistics derived from Sobel-Goodman test and it shows test statistic of 2.252 followed by a standard error worth of 0.189 with a p-value of 0.024 which is below the significance level 0.05 . Therefore, possible to conclude that the variable, attitude towards using acts a mediator in between the independent variables - critical factors; technological context, organizational context, environmental context, environmental context, perceived ease of use and perceived usefulness and dependent variable intention to adopt BDA.

\section{H. Discussion}

There are many challenges and barriers to the success of BDA adoption in apparel sector in the introductory phase. Previous studies have dealt with critical success factors for big data adoption. But there are limited studies which have analyzed how the both internal and external factors would affect for the users' attitudes and ultimately influence the intention to adopt BDA in apparel sector. This study is mainly woven around three main objectives and let's see how they have been achieved.

The first objective is to explore the key determinants responsible for explaining the variation of attitude towards using BDA and to calculate the weight of each factor. Based on the methodology and results presented, it emphasizes that the variables such as technological, and environmental factors as well as the behavioral factors such as perceived ease of use and perceived usefulness positively affects for the user' attitudes towards BDA adoption. All four factors derive a relationship with the variable, attitude towards using which performs statistically significant at a 0.01 level. However, the organizational context denotes a negatively correlated relationship with the variable, attitude towards using at a statistical significance level of 0.05 . This can be mainly due to data generated are not supportive enough to explain the effect of the organizational context on the attitude towards using BDA. Lautenbach, et al., [45] have also confirmed that factors from each of the $\mathrm{T}$ (Data-related Infrastructure Capabilities, Data management challenges, Privacy \& Security), O (Vision and strategy, Sponsorship and governance, Organizational structure, Talent Strategy \& capability Development) and E (Market Pressure, Big Data Pressure) contexts of the TOE framework were significantly indicating that this framework has been appropriate for gaining insights into BDA adoption and usage at an organizational level. In addition, Brock V \& Khan, [48] explained how the factors, perceived ease of use and perceived usefulness brought up by TAM framework significantly affected to the variation of the technology acceptance of BDA. When comes to the weight calculation of each of the determinants, statistical mean was used and high weight denoting independent variable could be introduced as technological context (4.136) while rest would be environmental context (4.103), perceived usefulness (3.966), perceived ease of use (3.865) and organizational context (3.790). Therefore, can summarize the first objective that the technological context, environmental context, perceived ease of use and perceived usefulness as key determinants which are responsible for explaining the variation of attitude towards using BDA while the explanatory power of the variable, organizational context remains at a minimum level.

Second objective was to examine the relationship among the variables; the attitude towards using BDA and the intention to adopt BDA. The results collected from a sample of 365 respondents confirm that there is a strong positive relationship between the variables attitude towards using and the intention to adopt BDA and it performs at a statistical significance of 0.01 which further confirms the explanatory power of the two variables. However, there is a dearth of studies which have analyzed the explanatory power of these two variables rather moving directly to the intention of adopting BDA from the critical factors. When comes to the real-world scenario, it is obvious that there is no way that critical factors could flow directly to intention to adopt BDA. As there is a human involvement in the adoption and implementation of BDA, it is important to give a focus on users' attitudes generated due to different external and internal factors which would ultimately decide the extent to which the user having the intention to adopt BDA. Jahangir \& Begum [49], have revealed that in their study on "The role of perceived usefulness, perceived ease of use, security and privacy, and customer attitude to engender customer adaptation in the context of electronic banking", that it is of paramount importance to ensure that people will actually use e-banking systems, as considerable amount of investment has been done in developing the system. Their study also suggests that in order to attract more users towards electronic banking, it is not going to be enough to merely introduce an e-banking system but also essential to develop the belief of usefulness of the system. Therefore, the findings emphasize the importance of assessing the relationship between attitude towards using and intention to adopt BDA as both BDA and e-banking systems are results of technology developments. 
The third and the final objective of this study is to assess the mediation effect of attitude towards using on the direct relationship between critical factors and the intention to adopt BDA. The findings of this study, which has been measured using Sobel-Goodman test denotes that the variable, attitude towards using performs a role as a mediator on the direct relationship between critical factors and the intention to adopt BDA. However, there is a dearth of studies which assess the mediating role of attitude towards using between the direct relationship of critical factors and intention to adopt BDA. But Jahangir \& Begum [49] in their study of customer adaptation in the context of electronic banking have contributed by providing support for the contention that customer attitude performs a mediating role in the link between perceived usefulness, ease of use, security and privacy, and customer adaptation. As both BDA and e-banking systems are outputs of technological innovations, it further proves that attitudes can perform a significant role as a mediator.

\section{CONCLUSION}

This study examined how certain factors would influence the extent to which BDA could be adopted in Sri Lankan context. The assessment of extent to which organizations' willing to adopt BDA was done based on the factors in the TOE framework and TAM model which were proven as influential in prior studies.

Data \& Analytics Report for the year 2017, released by MIT Sloan Management Review found that the percentage of organizations deriving competitive advantage from analytics is rising for the first time in four years [50]. It is found that the ability to innovate using analytics is driving resurgence of strategic benefits across all industries and this can be denoted as a finding arrived as a result of incorporating survey results and interviews with practitioners and scholars. The primary and as well as the main source of data for the MIT SMR's seventh annual analytics global survey has been the 2,602 responses received from business executives, managers, and analytics professionals from many organizations located all over the world [50]. In 2017, Lautenbach, et al., [45] confirmed that organization wished to be a differentiator among its rivals, needed to practice data-driven decision making which was supported by effective BDA usage in contrast to decision making based on intuition or gut feeling.

Technological context (Data-related infrastructure capabilities, Data management challenges \& Privacy \& Security), environmental context (Market Pressure \& Big Data Pressure), perceived ease of use and perceived usefulness can be presented as the most essential ingredients which would intensively affect towards enhancement of positive attitudes of users which would ultimately lead towards the intention of adopting BDA among the Sri Lankan, Apparel Sector. However, when comes to organizational context, it doesn't reflect a positive correlation towards the attitude towards using BDA. But the components in the organization context such as vision \& strategy, sponsorship and governance, organizational structure, talent strategy and development except firm size denoted a significant positive influence towards the attitude of using BDA when they were analyzed separately. Firm size didn't reflect a significant influence towards the attitude towards using and it could be due to generated data not enough to explain the dependence as well could be due to, there was no exact size-fit relationship as the adoption would mainly depend on the business requirements. Besides, the study presents evidences for a positive link between the variables; attitude towards using and intention to adopt BDA.

In addition to the presented perspectives of the critical factors, the study presented a new perspective of the mediator role performed by the variable, attitude towards using BDA on the direct relationship between critical factors and the intention to adopt BDA. This can be presented as a vital finding for the BDA practitioners and researchers. Finally, can conclude the study highlighting that the organizations which operate in apparel sector and which wish to promote data-driven decision making through greater use of BDA are specifically encouraged to focus on data-related infrastructure capabilities, vision and strategy, dynamic changes in consumer demands, transparency and understandability along with enhancement of effectiveness of the job roles of users. In return, it is expected that the implementation of BDA will lead to increase in organizational performance.

\section{LIMITATIONS AND FUTURE RESEARCH DIRECTIONS}

This study inherits several limitations which are not able to fulfill due to many resource restrictions. First, the focus of this study is on key apparel sector organizations in Sri Lanka regarding to the intention to adopt BDA. In this case, impact of organizational culture is ignored which may influence the level of attitude towards using along with the intention to adopt BDA. Future researchers has the opportunity to test the same research model in other organizations considering different cultural setups which they are exposed to, because the organizational setups and cultures vary from industry to industry; therefore, the findings of this study likely to vary when applied to different sector organizations [39]. In addition, the study was performed among limited number of respondents which might affect to the broader generalization. Furthermore, the focus of the study is on the intention to adopt BDA in a developing country; Sri Lanka. Thus, testing this model in developed countries grants the opportunity in enhancing the generalization of the study, as the severity of resistance to change from employees is greater in developing countries than in developed countries [51]. Also, this study is focusing to investigate the user intention to adopt BDA which totally neglects the system implementation. Therefore, future researchers could identify the developers/architects' intentions in developing and implementing BDA systems. Another limitation is that the study doesn't provide an implementation road map with respect to business applications. But high-level references regarding individuals' perceptions and factors affecting the intention to adopt BDA are given. Finally, the study is based on cross-sectional settings which restricts the measurement of the consistency in respondent behavior and to remove this gap and to significantly contribute to the knowledge, the study needs to be performed in a longitudinal setup. 


\section{REFERENCES}

[1] G. George , M. Haas and A. Pentland, "Big data and management.," Acad Manage J., vol. 57, no. 2, p. 321-326, 2014.

[2] E. Brynjolfsson, L. M. Hitt and H. H. kim, "Strength in Numbers: How Does Data-Driven Decisionmaking Affect Firm Performance?," 2011. [Online]. Available: [online] http://ssrn.com/abstract=1819486.

[3] L. Klie, "Getting closer to customers tops big data agenda.," CRM Mag., vol. 17, no. 1, pp. 15-15, 2013.

[4] S. Shiwei , G. Casey , Cegielskia, J. Lin and J. H. Dianne , "Understanding the Factors Affecting the Organizational Adoption of Big Data," JOURNAL OF COMPUTER INFORMATION SYSTEMS, 2016.

[5] L. G. Tornatzky and M. Fleischer, "The processes of technological innovation.," in Lexington, Mass: Lexington Books., 1990.

[6] "The future of Sri Lanka Apparel," 2018. [Online]. Available: http://www.ft.lk/apparel_fashion_design/The-future-of-Sri-LankaApparel/10404-665483. [Accessed 26 October 2018].

[7] R. U. Kuruppu, "'New policy for textile and clothing must emerge’," 12 January 2020. [Online]. Available: http://www.sundayobserver.lk/2020/01/12/\%E2\%80\%98new-policytextile-and-clothing-must-emerge.

[8] "May will be a "tough month" - Brandix CEO," 2020. [Online]. Available: http://bizenglish.adaderana.lk/may-will-be-a-tough-monthbrandix-ceo/. [Accessed 21 April 2020].

[9] S. Premaratne, "Analysing Sri Lankan lifestyles with data mining: two case studies of education and health," 2017.

[10] Gartner, "IT Glossary - Big Data," 2012. [Online]. Available: http://www.gartner.com/it-glossary/big-data.

[11] T. Lukoianova and V. Rubin, "Veracity Roadmap: Is Big Data Objective, Truthful and Credible?," Advances In Classification Research Online,, vol. 24, no. 1, pp. 4-15, 2014.

[12] M. Z. Elbashir, P. A. Collier and S. G. Sutton, "The role of organizational absorptive capacity in strategic use of business intelligence to support integrated management control systems," The Accounting Review, vol. 86, no. 1, pp. 155-184, 2011.

[13] D. Mungree, A. Rudra and D. Morien, "A framework for understanding the critical success factors of enterprise business intelligence implementation.," Chicago, 2013.

[14] K. R. Ramamurthy, A. Sen and A. P. Sinha, "An empirical investigation of the key determinants of data warehouse adoption," Decision Support Systems, vol. 44, no. 4, pp. 817-841, 2008.

[15] W. Yeoh and A. Koronios, "Critical success factors for business intelligence systems," Journal of Computer Information Systems, vol. 50, no. 3, pp. 23-32, 2010.

[16] O. Kwon, N. Lee and B. Shin, "Data quality management, data usage experience and acquisition intention of big data analytics," International Journal of Information Management, vol. 34, no. 3, pp. 387-394, 2014.

[17] N. A. M. Rafhi and S. A. Rahm, "Factors of Big Data Analytics in Enabling the Knowledge Management Practice," International Journal of Academic Research in Business and Social Sciences, vol. 7, no. 11, 2017.

[18] B. B. Jayasingh, M. R. Patra and D. B. Mahesh, "Security issues and challenges of big data analytics," pp. 204-208, 2016.

[19] W. Yeoh, A. Koronios and J. Gao, "Managing the Implementation of Business Intelligence Systems: A Critical Success Factors Framework," International Journal of Enterprise Information Systems, vol. 4, no. 3, 2008.

[20] H. Watson, D. Annino, B. Wixom, K. Avery and M. Rutherford, "Current practices in data warehousing.," Information Systems Management, vol. 18, no. 1, pp. 1-9, 2001.

[21] R. Bose and X. Luo, "Green It Adoption: A Process Management Approach.," International Journal Of Accounting and Information Management, vol. 20, no. 1, pp. 63-77, 2012.

[22] Y. Wang, Y. Wang and Y. Yang, "Understanding the determinants Of RFID adoption in the manufacturing industry.," Technological Forecasting and Social Change, vol. 77, no. 5, pp. 803-815, 2010.

[23] P. F. Hsu, K. L. Kraemer and D. Dunkle, "Determinants Of E-Business Use In Us Firms.," International Journal of Electronic Commerce, vol. 10, no. 4, pp. 9-45, 2006.
[24] K. Zhu, K. L. Kraemer and S. Xu, "The process of innovation assimilation by firms in different countries: A technology diffusion perspective on e-business," Management Science, vol. 52, no. 10, pp. 1557-1576, 2006.

[25] K. Zhu, S. T. Dong, S. X. Xu and K. L. Kraemer, "Innovation diffusion in global contexts: determinants of post-adoption digital transformation of European companies.," European Journal of Information Systems, vol. 15, no. 9, pp. 601-616, 2006b.

[26] K. Zhu and K. L. Kraemer, "Post-Adoption Variations In Usage and Value Of E-Business By Organizations: Cross-Country Evidence From The Retail Industry," Information Systems Research, vol. 16, no. 1, pp. 61-84, 2005.

[27] M. N. Masrek, A. Jamaludin and D. M. Hashim, "Determinants of strategic utilization of information systems: A conceptual framework," Journal of Software, vol. 4, no. 6, pp. 591-598, 2009.

[28] K. Agrawal, "Investigating the determinants of Big Data Analytics (BDA) adoption in Asian emerging economies.," 2015.

[29] F. D. Davis , "Perceived usefulness, perceived ease of use, and user acceptance of information technology," MIS Q., vol. 13, no. 3, 1989.

[30] P. Guriting and N. O. Ndubisi , "Borneo online banking: evaluating customer perceptions and behavioural intention.," Manage. Res. News, vol. 29, no. (1/2), pp. 6-15, 2006.

[31] K. Eriksson, K. Kerem and D. Nilsson , "Customer acceptance of internet banking in Estonia," Int. J. Bank Mark, vol. 23, no. 2, pp. 200-216, 2005.

[32] S. A. Gahtani , "The applicability of TAM outside North America: an empirical test in the United Kingdom.," Info. Resour. Manage. J., pp. 3746, 2001.

[33] K. Lancaster , "A new approach to consumer theory.," J. Polit. Econ., vol. 74, no. 2, pp. 132-157, 1966.

[34] H. C. Triandis , "Values, attitudes and interpersonal behaviour.," Unpublished paper, University of Nebraska Press, Lincoln, NE., 1979.

[35] J. Esteves and J. Curto , "A risk and benefits behavioral model to assess intentions to adopt big data.," J Intell Stud Bus., vol. 3, pp. 37-46, 2013.

[36] J. A. Castañeda , F. Muñoz-Leiva and T. Luque, "Web acceptance model (WAM): moderating effects of user experience.," Inf Manag., 2007.

[37] C. Brock , M. Blut , M. Linzmajer and B. Zimmer , "F-commerce and the crucial role of trust.," 2011.

[38] S. Muhammad , G. Changyuan , Z. LiLi , Fakhar Shahzad and H. Yanling , "Investigating the adoption of big data analytics in healthcare: the moderating role of resistance to change," Journal of Big Data, 2019.

[39] M. Shahbaz, C. Gao, L. Zhai, F. Shahzad and Y. Hu, "Investigating the adoption of big data analytics in healthcare: the moderating role of resistance to change," Journal of Big Data, 2019.

[40] A. Schüll and N. Maslan, "On the Adoption of Big Data Analytics: Interdependencies of Contextual Factors," 2018.

[41] Xinhua, "Asia\&Pacific," 2020. [Online]. Available: http://www.xinhuanet.com/english/2020-01/22/c_138726334.htm. [Accessed 221 2020].

[42] "LMD The Voice of Business," 2020. [Online]. Available: https://lmd.lk/export-corporate-brands-2/.

[43] S. Malladi and M. Krishnan, "Determinants of Usage Variations of Business Intelligence \& Analytics in Organizations - An Empirical Analysis.," Milan, 2013.

[44] H. Gangwar, "Understanding the Determinants of Big Data Adoption in India: An Analysis of the Manufacturing and Services Sectors," Information Resources Management Journal, vol. 31, no. 4, 2018.

[45] P. Lautenbach, K. Johnston and T. Adeniran-Ogundipe, "Factors influencing business intelligence and analytics usage extent in South African organisations," S.Afr.J.Bus.Manage, vol. 48, no. 3, 2017.

[46] K. J. Preacher and G. J. Leonardelli, "Calculation for the Sobel Test," 2001. [Online]. Available: http://quantpsy.org/sobel/sobel.htm.

[47] B. Azvine, Z. Cui and D. D. Nauck, "Towards real-time business intelligence," BT Technology Journal, vol. 23, no. 3, pp. 214-225, 2005.

[48] V. Brock V and H. U. Khan, "Big data analytics: does organizational factor matters impact technology acceptance?," J Big Data, 2017.

[49] N. Jahangir and N. Begum, "The role of perceived usefulness, perceived ease of use, security and privacy, and customer attitude to engender 
customer adaptation in the context of electronic banking," African Journal of Business Management, vol. 2, no. 1, pp. 032-040, 2008.

[50] S. Ransbotham and D. Kiron, "Analytics as a Source of Business Innovation," MIT Sloan Management Review, 2017.
[51] M. Nejati, S. Rabiei and C. J. Chiappetta Jabbour, "Envisioning the invisible: understanding the synergy between green human resource management and green supply chain management in manufacturing firms in Iran in light of the moderating effect of employees' resistance to change.," 2017. 